\title{
Dedication
}

\section{Toshio Obi: International Leader for Advancing E-Government Through Education, Innovation and Effective Management}

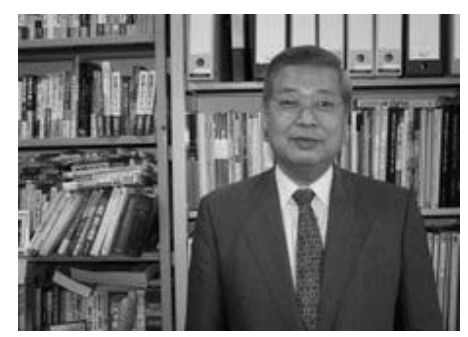

Throughout his career as a founder and director of the Waseda University Institute of e-Government, Dr. Obi has inspired and initiated a number of programs that are widely recognized as essential to meeting human resource requirements of rapidly evolving e-Governance. In recognition of his international leadership in expanding the professional standards of Chief Information Officers (CIO), he was elected President of the International Academy of CIO in 2008. The Waseda International Forum on CIO, ICT and e-Governance have been widely known and feature many top leaders in the field. $\mathrm{He}$ also has directed e-Government programs of APEC, UNDP, ITU and other international organizations.

The inspiration behind the Waseda University eGovernment Rankings, together with research team, have prepared 5 annual rankings that are widely publicized and the main e-Government benchmarking initiative in the Asia Region. Several important benchmarks as well as a number of specific indicators are applied to the e-Government programs of 34 jurisdictions. Drawn from this extensive empirical data are the rankings of these governments.

I-Ways highly values Dr.Obi's service as an advisor, close collaboration in several projects and for selecting this journal to publish the full 2009 rankings report.

Russell Pipe, Editor 